\title{
Individual chronobiological regularity in track-and-field sprint
}

Kozina Zh.L. ${ }^{1 \mathrm{ABCDE}}$, Prokopenko I.F. ${ }^{2 \mathrm{ABC}}$, Cretu M. ${ }^{3 \mathrm{ADE}}$, Chaika O.I. ${ }^{4 \mathrm{ABCDE}}$, Ryepko O.A. ${ }^{1 \mathrm{CDE}}$, Osiptsov A.V. ${ }^{5 \mathrm{CDE}}$, Razumenko T.O. ${ }^{6 \mathrm{CDE}}$, Kudryavtsev M.D. ${ }^{7,8,9,10 \mathrm{ADE}}$, Polianskyi A.O. ${ }^{8 \mathrm{BCD}}$

${ }^{1}$ Department of Olympic and Professional Sports and Sports Games, H. S. Skovoroda Kharkiv National Pedagogical University, Ukraine

${ }^{2}$ Department of Economic Theory, H. S. Skovoroda Kharkiv National Pedagogical University, Ukraine

${ }^{3}$ Faculty of Science, Physical Education and Informatics, University of Pitesti, Romania

${ }^{4}$ Department of Physical Education, Kharkov National Air Force University, Ukraine

${ }^{5}$ Department of Physical Education and Health, Mariupol State University, Ukraine

${ }^{6}$ Faculty of Foreign Philology, H. S. Skovoroda Kharkiv National Pedagogical University, Ukraine

${ }^{7}$ Department of Physical Training, Krasnoyarsk State Pedagogical University of V.P. Astafyev, Russia

${ }^{8}$ Siberian Federal University, Russia

${ }^{9}$ Reshetnev Siberian State University of Science and Technology, Russia

${ }^{10}$ The Siberian Law Institute of the Ministry of Internal Affair of Russia, Russia

${ }^{11}$ Department of Criminal Law Disciplines, H.S. Skovoroda Kharkiv National Pedagogical University, Ukraine

Authors' Contribution: A - Study design; B - Data collection; C - Statistical analysis; D - Manuscript Preparation; E - Funds Collection.

$\begin{array}{ll}\text { Abstract } & \\ \text { Purpose: } & \text { to identify the patterns of individual dynamics of competitive performance in track and field sprint. } \\ \text { Material: } & \text { The study involved a highly qualified athlete (running for short distances, long jumps). } \\ \text { Results: } & \begin{array}{l}\text { In the sinusoidal functions of the competitive performance of the athlete, the period of oscillation was } 32 \text { to } \\ 48 \text { days. It is shown that the period of the sinusoidal function of the dynamics of competitive performance } \\ \text { (about } 30-40 \text { days) coincides with the period of the ovarian cycle of the athlete. A reliable relationship } \\ \text { between the } 400 \mathrm{~m} \text { run time and intuitive biorhythm values was established (the oscillation period is } 38 \text { days } \\ (\mathrm{r}=-0.58, \mathrm{p}<0.05) \text { ). The data obtained coincided with the period of fluctuations in the sports form. Training } \\ \text { programs are built on the patterns of ups and downs of the functional state. }\end{array} \\ \text { Conclusions: } & \begin{array}{l}\text { Regularities of the individual dynamics of the sports form make it possible to provide the necessary } \\ \text { correspondence between the state of the organism and the dynamics of the loads. } \\ \text { sprint, athletics, models, biorhythm. }\end{array}\end{array}$

\section{Introduction}

At present, the urgency of the problem of the athlete's withdrawal to the peak of the sports form to the main competitions is rising. Lombardo $\mathrm{M}$. et al. [1] note that this problem is based on the difficulties of accurately determining the moment of maximum supercompensation. The moment of supercompensation is most favorable to the manifestation of the maximum capabilities of the athlete. Marks T. [2], Mujika I. [3, 4] indicate that the complexity of determining supercompensation is associated with the heterochrony of the restorative processes of various body systems. The complexity of determining the moment of supercompensation is related to the individual characteristics of each athlete. Research by Schumacher Y.O. [5], Pyne D.B. et al. [6] showed that the process of changing the functionality and performance of an athlete is wavy in nature. It is on this regularity that the principle of wave-like dynamics of loads in the training process is based. In the work of Beashel P. et al. [7] it is shown that this principle is the basis for the structural periodization of the training process.

Platonov V.N. [8] presents the theoretical basis for the periodization of the training process. In the structural

(C) Kozina Zh.L., Prokopenko I.F., Cretu M., Chaika O.I., Ryepko O.A., Osiptsov A.V., Razumenko T.O., Kudryavtsev M.D., Polianskyi A.O., 2018

doi:10.15561/18189172.2018.0306 elements of the training process distinguish: small waves (up to 24 hours, from 1 to 7 days); average waves (lasting about a month or several months); long waves (lasting about a year or several years). Based on this, structural elements of sports training are built: microcycles, mesocycles, macrocycles.

This structure of the training process underlies its periodization. Kozina Z . et al. [9] showed that the issue of specifying the volume, intensity and nature of the loads remains relevant. At present, specific selection of loads is carried out intuitively by the trainer. In the same way, the dynamics of loads of different directions during microcycles, mesocycles and macrocycles is constructed. There are general recommendations for alternating loads of different directions in the structural elements of the training process. However, individual selection of the direction and magnitude of the load is a difficult task. Such selection depends on the wave-like change in the athlete's functional state. To solve this problem, it is expedient to use mathematical models for changing the athlete's functional state. This will accurately determine the periods of ups and downs of the functional state. This will also give an opportunity to individually adjust the training process $[10,11]$.

In the literature, there are data on the existence of certain regularities of a wave-like change in the functional state of each athlete. The athlete's functional state is 
reflected in competitive performance. In some works [10, 11] it was revealed that the dynamics of individual gaming performance in basketball is described by sinusoidal functions (period 28-32 days). It was shown that the process of changing the competitive performance is expedient to consider from the point of view of oscillatory processes [11]. To describe this pattern, a sinusoidal function is used. These regularities are described by sinusoidal, cubic or quadratic functions [12].

The application of the regression model is effective in practical work. This model allows to predict the time of increase and decrease of individual performance and functional status of athletes. This helps to adjust the training programs and determine some of the individual characteristics of the athletes.

Wavy character of the dynamics of the athlete's functional state has a diverse nature. It is due to external and internal causes [8]. Internal causes include: the nature of the loads; individual features of the recovery processes. External factors include chronobiological factors. It can be concluded that the internal and external factors of the undulation of the functional state determine the individual dynamics of the ups and downs of the sports form. In such cases it is recommended to use the theory of biorhythms $[1,14,15]$. It should be noted that the main structural elements of the periodization of the training process correspond to natural biorhythmic fluctuations.

The study describes the characteristics of the main biorhythms [16, 17]. Rhythms are classified according to the length of the period. The most studied are circadian rhythms (a period of about 24 hours). The results of the study of circadian rhythms are presented in various studies [18-21]. There are also biorhythms with periods: 7-14 days; 21-43 days; about a year; about a few years $[16,17]$.

In the preparation of athletes, the structural elements of periodization correspond to the given classification of biorhythms. Biorhythms with a period of $7 \pm 3$ days correspond to microcycles in the training process. Biorhythms with a period of $21 \pm 3$ and $30 \pm 5$ days correspond to mesocycles or their elements. Annual rhythms correspond to the annual cycles of training athletes.

There is also a theory of three biorhythms that begin to act at the time of human birth [22, 23]. According to various studies $[22,24,25]$ this theory is unproven. Other data $[23,26]$ indicate that there are interrelationships of competitive performance with the values of the three biorhythms.

At present, the hypothesis of the existence of three congenital biorhythms is controversial [27]. Individual patterns of the functional state and dynamics of the competitive performance of athletes allow you to determine the nature, volume and intensity of physical exertion. This allows you to adjust the training process, which takes the athlete to the peak of the functional state to the main competitions.

This provision is relevant for representatives of all sports. This provision has special relevance for sports with the maximum manifestation of physical and mental capabilities. These sports include track and field sprint.

It has been established $[1,7,8]$ that track and field sprint makes high demands on the development of speed and speed-strength capabilities of athletes. At competitions from a sprinter, the maximum manifestation of these qualities is required. These qualities have undulating dynamics of development. Therefore, to correct the training process sprinters need to select the load by nature, volume and intensity. This choice takes into account the patterns of individual dynamics of the functional state of athletes.

The purpose of the work is to reveal the patterns of individual dynamics of competitive performance in track and field sprint.

\section{Material and methods.}

Participants. In the study participated a high-level athlete. She specializes in running short distances and long jumps. Athlete is the European Athletics Champion 2010, a World Paralympic and Paralympic Games Champion among the athletes with visual impairments (T12 category) in 2016.

Organization of the study. Individual features of the functional state of the athlete were analyzed within 24 hours. The subjective feelings of the athlete were recorded regarding the desire to exercise.

Models of competitive performance in a one-year training cycle from 2015 to 2017 (sinusoidal regression) are compiled.

The dynamics of the athlete's competitive performance at the international competitions from 1997 to 2015 was analyzed (running at $400 \mathrm{~m}, 200 \mathrm{~m}, 100 \mathrm{~m}$ and $60 \mathrm{~m}$.) Models of nonlinear regression were made. Nonlinear regression lines allowed to forecast the results until 2017. The real results of 2016 were compared with the forecast. The values of various biorhythms were determined (23 days - physical biorhythm, 28 days - emotional biorhythm, 32 days - intellectual biorhythm, 38 days - intellectual biorhythm, 43 days - intuitive biorhythm. familiarize program «Biorhythm expert» (http://www.tucows.com/ preview/332490/Biorhythm-Expert). It was conducted correlation analysis of competitive performance with the biorhythm value.

Statistical analysis. Based on the results in the run, sinusoidal regression models of the dynamics of individual competitive performance were compiled. The Mathcad program was used. Dynamics of competitive performance was described by polynomial functions. The program SPSS and EXCEL was used. A correlation analysis of competitive performance indicators was also conducted.

\section{Results.}

It was revealed that the peak of a functional state of the athlete is observed in the evening hours after 18-00. Competitive results in the evening also turned out to be somewhat higher. The obtained results confirm the studies of other authors on the existence of individual 
characteristics of circadian rhythms [28-30]. We adjusted the training process with the transfer of the main loads for evening workouts. The time of evening training was also shifted to later hours from 19-00 to 20-30.

At the next stage, it was analyzed perimonth fluctuations in competitive performance. For this, regression models of performance dynamics on shorter segments were analyzed. These segments included a oneyear preparation cycle or several mesocycles. To do this, sinusoidal performance models were built. This allowed us to determine the individual periods of ups and downs. An example of such a model is shown in Figure 1. The performance of an athlete at a distance of $200 \mathrm{~m}$ in years 2015-2017 is described by a sinusoidal function:

where: $\mathrm{x}=10$ days, $\mathrm{y}(\mathrm{x})=3,4 \sin (1.2 \mathrm{x})+27, \quad(1)$

$\mathrm{y}$ - running time of distance $200 \mathrm{~m}$.

The period of fluctuations in competitive performance is 38 days (Figure 1).

At longer time intervals, the athlete's competitive performance in the $200 \mathrm{~m}$ run was described by the equation of the sinusoidal function:

$$
y(x)=-3.4 \sin (0.2 x)+27,(2)
$$

where $\mathrm{x}=10$ days,

$\mathrm{y}$ - running time of distance $200 \mathrm{~m}$.

Similarly, sinusoidal models of competitive performance of athlete in running at $60 \mathrm{~m}, 80 \mathrm{~m}, 100 \mathrm{~m}$, 120 m, 150 m were constructed.

In the sinusoidal functions of the competitive performance of the athlete, the period of oscillation was 32 to 48 days. The results obtained mean that the maximum level of the functional state of the athlete and the manifestation of maximum possibilities appears with a periodicity of 32 to 48 days. In the same way, the maximum decline in functionality is also changing. When comparing the revealed regularity of the dynamics of the functional state of the athlete with her ovulatory cycle, it was found that the duration of the ovulatory cycle of the athlete also ranges from 32 to 48 days. The peak of effectiveness falls on the second phase of the ovulatory cycle. Thus, the period of the sinusoidal function of the dynamics of competitive performance coincided with the period of the ovarian cycle of the athlete. Accounting for these regularities allows you to adjust the training process. It is based on individual ups and downs of the athletic form. Recommendations were given to correct the training process.

The dynamics of the competitive performance of the athlete at international competitions from 1997 to 2015 (running at $400 \mathrm{~m}, 200 \mathrm{~m}, 100 \mathrm{~m}$ and $60 \mathrm{~m}$ ) was also analyzed.

Correlation coefficients between the competitive performance from 1997 to 2015 and the values of individual biorhythms were calculated. A reliable relationship was found only between the time of running a distance of 400 $\mathrm{m}$ and the values of the intuitive biorhythm. The period of oscillation of this biorhythm is 38 days ( $r=-0.58, \mathrm{p}<0.05)$. These data coincided in the features of the dynamics of the competitive performance of the athlete. However, for shorter distances, no relationships were found.

Next, nonlinear regression models were compiled describing the dynamics of the athlete's competitive performance in the multi-year period. The decision of models allowed to make the forecast of results for years

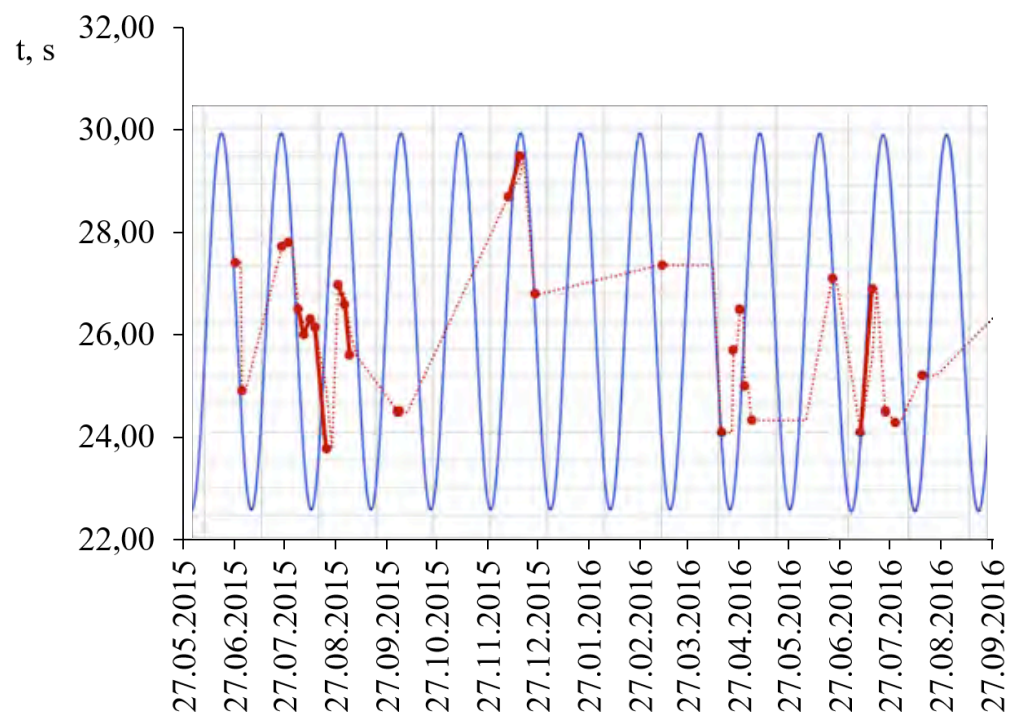

Date: day, month, year

Fig. 1. Individual competitive performance of an athlete at a distance of $200 \mathrm{~m}$; the period of oscillations covers several microcycles is 38 days:

\section{- results in international competitions;}

from 2015 to 2017. 
2016-2017. Training programs were adjusted for the revealed patterns of ups and downs of the functional state.

Competitive performance of the athlete (from 1997 to 2016) and the forecast until 2017 is described by the equation of polynomial regression (Fig. 2 - distance $400 \mathrm{~m}) ; \mathrm{R}^{2}=0.93$. This indicates a high accuracy of approximation.

Similarly, polynomial regression curves (the period from 1997 to 2015) were analyzed at distances of 200 $\mathrm{m}, 100 \mathrm{~m}, 60 \mathrm{~m}$. The regression lines were extended until 2017. This allowed us to compare the competitive performance of 2016 with the forecasted result on the regression lines.

The training programs were adjusted according to the patterns of the individual dynamics of competitive performance for the athlete's exit to the peak of the sports form for the Paralympic 2016.

The data obtained confirm other studies [11, 12]. These studies have shown that in qualified athletes competitive performance is subject to periods of 23 to 50 days. Periods of more than 30 days correspond to changes in the mental and intuitive sphere. Correction of training programs was built according to this feature of the athlete. For the athlete, first need to understand the meaning of the proposed exercises: to reproduce in the mind various actions; independent installations for activating regenerative processes, staying in the nature zone are very effective; as a means of recovery suits calm music, such as "Relax" or "Trance" with video accompaniment.

In the training process of the athlete these recommendations were taken into account. As a result, at the Paralympic Games in 2016 the athlete showed results, slightly higher than the forecast. She became the World Champion and the silver medalist of the Paralympic Games of 2016.

\section{Discussion.}

The results obtained by us agree with other studies
[12]. The authors established the existence of a periodicity of fluctuations in the competitive performance of qualified athletes. It was revealed that the dynamics of individual gaming performance is described by sinusoidal functions with periods of 28-32 days. The data obtained can be useful for predicting: the individual gaming performance of athletes; determining the individual characteristics of players; adjusting training programs.

Other data $[9,10]$ were confirmed that the process of changing the competitive performance is expedient to consider from the point of view of oscillatory processes. The most acceptable function for describing this pattern is the sinusoidal function.

It is shown that for high-skill sprinters [12], the regression model of the individual dynamics of the effectiveness of competitive activity is subject to sinusoidal dependence. It is described by the regression equation

$$
y=a+b \sin ((2 \pi / t)(T-c)),
$$

where $y$ - the result, $T$ - time interval (day from the first contest being analyzed), $a$ - the average value of the athlete's performance, $b$ - the amplitude of the athlete's performance, $t$ - the period of oscillations of the athlete's gaming performance, $c$ - the period value at the time of the first contest being analyzed.

Other data [9] have been confirmed that the application of the regression sinusoidal model is effective in practical work. The model allows to predict the time of increase and decrease of individual effectiveness. This helps to adjust the training programs and determine some of the individual characteristics of the athletes. However, for representatives of athletics sprint athletes with visual impairments, these patterns were revealed for the first time.

In our other studies, it has also been shown [12] that skilled basketball players have individual dynamics of the effectiveness of game actions. It is described by sinusoidal functions. This pattern is periodic ups and downs, repeated

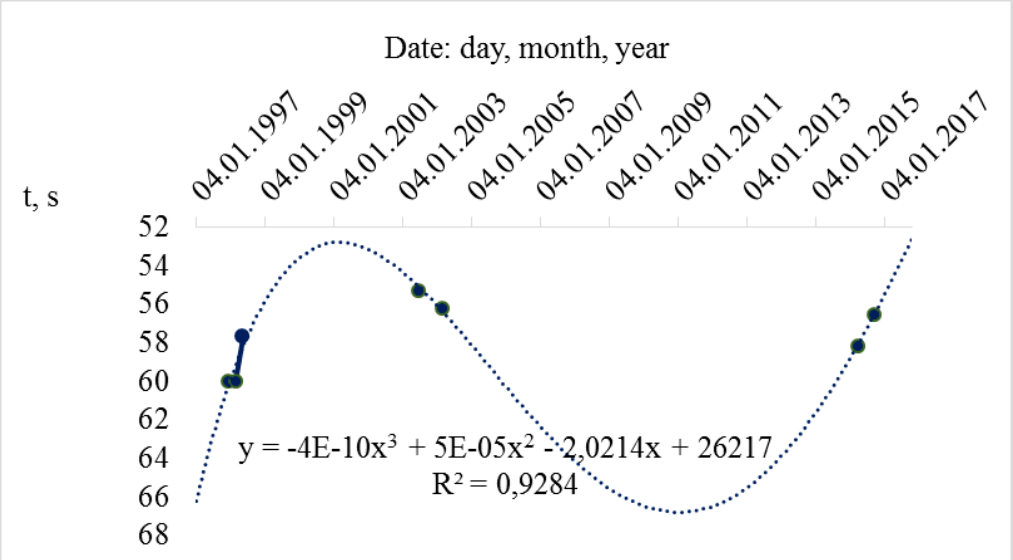

Fig. 2. Individual competitive performance of the athlete at a distance of $400 \mathrm{~m}$ :

\section{- results in international competitions;}

........ - a graph of polynomial regression, describing the dynamics of competitive performance from 1997 to 
in a certain sequence. These regularities are also described by cubic or quadratic regression equations.

In another study [12], it was found that the relationship between the effectiveness of gaming activities with the level of physical, emotional and intellectual biorhythms is individual for each player. The correlation coefficient ranges from $0.61(\mathrm{p}<0.05)$ to a complete absence or even a negative relationship. This can be explained by the different magnetosensitivity of the players or the different levels of their athletic preparedness.

However, at present, the hypothesis of the existence of three congenital biorhythms causes disagreement [22, 24]. It should be noted that our studies show the presence of regularities in the dynamics of the competitive performance of athletes of high qualification. These patterns can be used in practical work. In this case, there can be observed and not observed the relationship of effectiveness with the values of the three biorhythms.

In our study, a correlation was found between the values of the intuitive biorhythm of the athlete and the performance at a distance of $400 \mathrm{~m}$. The period of oscillation of this biorhythm is 38 days.

This value coincided with the data on the oscillation period of the sinusoidal function (running time at $60 \mathrm{~m}$, $80 \mathrm{~m}, 100 \mathrm{~m}, 120 \mathrm{~m}, 150 \mathrm{~m}, 200 \mathrm{~m}$ and $400 \mathrm{~m})$. The period of fluctuations in effectiveness also coincided with the values of the period of the ovarian cycle of the athlete. The obtained data testify to the presence of regularities of ups and downs of the functional state. This must be taken into account when planning training loads in the structural elements of the training process.

The existence of an interrelation between the values of congenital biorhythms was revealed only for a distance of $400 \mathrm{~m}$ for a biorhythm with a period of 38 days. This corresponds to data indicating the effect of biorhythms on human performance [23, 26]. However, the obtained data also testify to the relativity of this hypothesis [22, 24]. For other distances, no reliable relationship was found.

The data obtained by us refine the results of the regression analysis of the dynamics of competitive performance [12]. In addition, the results of studies on the coincidence of these patterns in women have been confirmed [12]. We can assume the summation of internal and external parameters of influence on competitive performance.

The results obtained by us are of great importance in practical work. This allows you to adjust the training process in accordance with the individual ups and downs of the sports form.

The obtained results confirm the necessity of observing the principle of undulation of training loads [8, 31, 32]. This allows you to more accurately determine the periods of increases and decreases in training loads. These periods correspond to changes in the functional state of athletes. As a result, it became possible accurately to determine the periods of increase and decrease in training loads. These periods are consistent with the natural increase and decrease in the functional state. In this case, the proposed models make it possible to calculate "waves" of different values [8]:

- small, characterizing the dynamics of loads in microcycles. They cover a few days;

- medium, expressing the general tendency of loads of several small "waves" within the mesocycles (medium cycles) of training;

- large, characterizing the general trend of the average "waves" in the period of large training cycles.

Adequate construction of sports training is to properly measure the fluctuations in the loads of different directions and magnitudes with the dynamics of the athlete's functional state. Identifying and taking into account the regularities of the individual dynamics of the sports form allows to ensure the necessary correspondence between the state of the organism and the dynamics of the loads.

\section{Conclusions.}

1. Individual characteristics of the functional state of the athlete were analyzed within 24 hours. The results confirm the data on the existence of individual characteristics of circadian rhythms.

2. It is shown that in the sinusoidal functions of the competitive performance of the athlete, the period of oscillation was 32 to 48 days. A reliable relationship between the $400 \mathrm{~m}$ run time and intuitive biorhythm values was established (the oscillation period is 38 days $(r=-0.58, p<0.05)$ ). The data obtained coincided with the period of fluctuations in the sports form.

3. Our approaches allowed the athlete to win the World Championship and the silver medal of the Paralympic Games in 2016. The carried out researches can serve as an algorithm for determining the regularities of the individual dynamics of the condition of athletes. This allows you to adjust the training process in preparation for the main competitions.

\section{Financing}

The research is conducted according to:

- the consolidating plan of research work in the sphere of physical culture and sport for 2011-2015 on a subject 2.4 «Theoretical and methodical bases of individualization in physical training and sport» (№ of the state registration 0112U002001);

- the research work of Ministry of Education and Science of Ukraine for 2013-2014. «Theoretical and methodical bases of application the information, pedagogical and medical-biological technologies for formation of healthy lifestyle» (№ of the state registration 0113U002003);

- the research work of Ministry of Education and Science of Ukraine for 2015-2016. «Theoretical and methodical bases of means application the information, pedagogical, medical-biological orientation for motor and spiritual development and formation of healthy lifestyle» (№ of the state registration 0115U004036).

- the research work of Ministry of Education and Science of Ukraine for 2017-2018. «Theoretical and methodical bases of application of information, medicalbiological and pedagogical technologies for realization of 
individual physical, intellectual and spiritual potential and formation of healthy lifestyle» (№ of the state registration 0117U000650)

\section{Conflict of interest.}

The authors state that there is no conflict of interest.

\section{References:}

1. Lombardo Michael P, Deaner Robert O. You can't teach speed: sprinters falsify the deliberate practice model of expertise. PeerJ. 2014; 06(26). doi:10.7717/peerj.445

2. Marks T. A sporting chance. Apollo-the International Art Magazine. 2016; 184(645): 17-17.

3. Mujika I. Intense training: the key to optimal performance before and during the taper. Scand J Med Sci Sports, 2010; 20(2): 24-31.

4. Mujika I. Tapering for triathlon competition. J Human Sport \& Exercise, 2011; 2(1): 264-270.

5. Schumacher YO. The 4000-m team pursuit cycling world record: theoretical and practical aspects. Msse, 2002; 34(6): 1029-1036.

6. Pyne DB, Mujika I, Reilly T. Peaking for optimal performance: research limitations and future directions. $J$ Sports Sciences, 2009; 27(3): 195-202.

7. Beashel P, Taylor J. Advanced Studies in Physical Education and Sport. UK: Thomas Nelson and Sons Ltd.; 1996.

8. Platonov VN. Periodization of sports training. General theory and its practical applications. Kiev: Olympic Literature; 2013. (in Russian)

9. Kozina Z, Repko O, Ionova O, Boychuk Y, Korobeinik V. Mathematical basis for the integral development of strength, speed and endurance in sports with complex manifestation of physical qualities. Journal of Physical Education and Sport, 2016; 16(1): 70-76. doi:10.7752/jpes.2016.01012

10.Jagiello W, Jagiello M, Kalina RM, Barczynski BJ, Litwiniuk A, Klimczak J. Properties of body composition of female representatives of the Polish national fencing team - the sabre event. Biology of Sport, 2017;34(4):401-406. doi:10.5114/ biolsport.2017.70526

11.Kozina Z., Iermakov S., Bartík P., Yermakova T., Michal $\mathrm{J}$. Influence of self - regulation psychological and physical means on aged people's functional state. Journal of Human Sport and Exercise, 2018;13(1), 99-115. doi:10.14198/ jhse.2018.131.10

12.Kozina ZhL, Voskoboinik AC, Grin LV. Application of methods of multidimensional and nonlinear regression analysis to reveal the laws of individual dynamics of competitive performance in basketball. Health, sport, rehabilitation, 2015;1:40-42.

13.Ali G. Loads of Training Geared to the Pattern of Daily BioRhythm on Some Vital Functions and Development of 800-meter Runners. World Journal of Sport Sciences, 2010; 3 (S): 1250-1254.

14.Araujo LG. Waterhouse J., Edwards B. Henrique E., Santos R., Tufik S., Túlio de Mello M. Twenty-four-hour rhythms of muscle strength with a consideration of some methodological problems. Biological Rhythm Research, 2011; 42(6): 473490.

15.Bardis K, Atkinson G. Effects of time of day on power output and thermoregulation responses during cycling. Biology of exercise, 2008; 4:17-28.

16. Hines TM. Comprehensive review of biorhythm theory. Psychology Department, Pace University, Pleasantville, NY. Psychol Rep. 1998;83(1):19-64.

17.Shaffer JW, Schmidt CW, Zlotowitz HI. Fisher RS. Biorhythms and Highway Crashes. Are They Related? Arch
Gen Psychiatry. 1978;35(1):41-46.

18.Bessot N, Moussay S, Clarys JP, Gauthier A, Sesboüé B, Davenne D. The influence of circadian rhythm on muscle activity and efficient force production during cycling at different pedal rates. J. Electromyogr. Kinesiol. 2007; 17: 176-183.

19.Calogiuri G, Weydahl A, Carandente F. Effects of Sleep Loss on the Rest-Activity Circadian Rhythm of Helpers Participating in Continuous Dogsled Races. Biol. Res. Nurs. 2014; 16: 123-133.

20.Chaâri N, Frikha M, Mezghanni N. Time-of-day and warmup durations effects on thermoregulation and anaerobic performance in moderate conditions. Biological Rhythm Research. 2013; 10: 46-49.

21.Drust B, Waterhouse J, Atkinson G, Edwards B, Reilly T. Circadian rhythms in sports performance - an update. Chronobiology International, 2005; 22(1): 21-44.

22.Joncas SX, Carrier N, Nguyen M, Farand P. Biorhythm Theory Does Not Predict Admission for Acute Myocardial Infarction. The Journal of Alternative and Complementary Medicine, 2011; 17(2): 143-146.

23.Paugschová B, Gereková J, Ondráček J. Biorythmic changes in the development of velocity and power abilities in biathlon. Studia sportiva. 2010; 4:25-34.

24.Raut TS, Kaware SHH. Comparative study of Biorhythms with Various physical fitness components. International Referred Research Journal, 2011;4:32-33.

25.Mahoney P, Miszkiewicz JJ, Chapple S, Le Luyer M, Schlecht SH, Stewart TJ, et al. The biorhythm of human skeletal growth. Journal of Anatomy. 2018;232(1):26-38. doi:10.1111/joa.12709

26.Sokolova VS, Dvornikov PA. Biorithms and their influence on the effectiveness of the training process and the results of competitions of the competition-biathlonists. Modern problems of science and education, 2015; 4:36-42.

27.Wolcott JH, McMeekin RR, Burgin RE, Yanowitch RE. Correlation of general aviation accidents with the biorhythm theory. Hum Factors. 1977;19 (3): 283-93.

28.Georgopoulos NA, Rottstein L, Tsekouras A, Theodoropoulou A, Koukkou E, Mylonas P, Polykarpou G, Lampropoulou E, Iconomou G, Leglise M, Vagenakis AG, Markou KB. Abolished circadian rhythm of salivary cortisol in elite artistic gymnasts. Steroids. 2011; 76 (10): 353-357.

29.Jarraya M, Jarraya S, Chtourou H. The Impact of Partial Sleep Deprivation on the Diurnal Variations of Cognitive Performance in Trained Subjects. Procedia - Social and Behavioral Sciences, 2013; 3 (82): 392-396.

30.Jourkesh M, Keikha BM, Sadri·l,-Ojagi A. The Effects of time of day on Physical fitness Performance in college-aged men. Annals of Biological Research, 2011; 2 (2): 435-440.

31.Kalina RM, Jagiello W, Chodala A. The result of "testing fights in a vertical posture" as a criterion of talent for combat sports and self-defence - secondary validation (part II: the accuracy). Archives of Budo Science of Martial Arts and Extreme Sports, 2016;12.

32.Osipov AY, Kudryavtsev MD, Iermakov SS, Jagiello W. Criteria for effective sports selection in judo schools - on example of sportsmanship's progress of young judo athletes in Russian Federation. Archives of Budo. 2017;13:179-186. 
Kozina Zh.L.; (Corresponding author); http://orcid.org/0000-0001-5588-4825; Zhanneta.kozina@gmail.com; Department of Olympic and Professional Sports and Sports Games, H.S. Skovoroda Kharkiv National Pedagogical University; Alchevskyh str. 29, Kharkov, 61002, Ukraine.

Prokopenko I.F.; http://orcid.org/0000-0002-1190-852X; Department of Economic Theory, H.S. Skovoroda Kharkiv National Pedagogical University; Alchevskyh str. 29, Kharkov, 61002, Ukraine.

Cretu M.; https://orcid.org/0000-0003-1934-0534; Faculty of Science, Physical Education and Informatics, University of Pitesti; Str. Targul din Vale, nr.1, 110040 Pitesti, Arges, Romania.

Chaika O.I.; http://orcid.org/0000-0002-6340-1907; Department of Physical Education, Kharkov National Air Force University; ul. Klochkovskaya, 228, 61000, Kharkov, Ukraine.

Ryepko O.A.; http://orcid.org/0000-0001-6879-6015; Department of Olympic and Professional Sports and Sports Games, H.S. Skovoroda Kharkiv National Pedagogical University; Altshevskih str. 29, Kharkov, 61002, Ukraine.

Osiptsov A.V.; http://orcid.org/0000-0002-1640-2632; Mariupol State University; Budivelnykiv Ave., 129a, Mariupol, 87500, Ukraine.

Razumenko T.O.; http://orcid.org/0000-0002-0682-3812; Faculty of Foreign Philology, H. S. Skovoroda Kharkiv National Pedagogical University; Altshevskih str. 29, Kharkov, 61002, Ukraine.

Kudryavtsev M. D.; http://orcid.org/0000-0002-2432-1699; Siberian Federal University; 79, Svobodny pr., Krasnoyarsk, 660041, Russia.; Reshetnev Siberian State University of Science and Technology; Office A-406, 31, Krasnoyarsky Rabochy Av., 660014, Krasnoyarsk, Russia.; The Siberian Law Institute of the Ministry of Internal Affair of Russia; Rokossovskia str., 20, Krasnoyarsk, 660131, Russia.; Krasnoyarsk State Pedagogical University of V.P. Astafyev; Ada Lebedeva Street, 89, Krasnoyarsk, 660049, Russia.

Polianskyi A.O.; http://orcid.org/0000-0003-3005-8206; Department of Criminal Law Disciplines, H.S. Skovoroda Kharkiv National Pedagogical University; Alchevskyh str. 29, Kharkov, 61002, Ukraine.

Cite this article as: Kozina ZhL, Prokopenko IF, Cretu M, Chaika OI, Ryepko OA, Osiptsov AV, Razumenko TO, Kudryavtsev MD, Polianskyi AO. Individual chronobiological regularity in track-and-field sprint. Pedagogics, psychology, medical-biological problems of physical training and sports, 2018;22(3):149-155. doi:10.15561/18189172.2018.0306

The electronic version of this article is the complete one and can be found online at: http://www.sportpedagogy.org.ua/index.php/PPS/issue/archive

This is an Open Access article distributed under the terms of the Creative Commons Attribution License, which permits unrestricted use, distribution, and reproduction in any medium, provided the original work is properly cited (http://creativecommons.org/licenses/by/4.0/deed.en).

Received: 20.11.2017

Accepted: 20.12.2017; Published: 30.06.2018 